\title{
Thioalkalivibrio thiocyanoxidans sp. nov. and Thioalkalivibrio paradoxus sp. nov., novel alkaliphilic, obligately autotrophic, sulfur- oxidizing bacteria capable of growth on thiocyanate, from soda lakes
}

\footnotetext{
${ }^{1}$ Institute of Microbiology RAS, Prospect 60-let Octyabrya 7/2, 117811 Moscow, Russia

2 Kluyver Institute of Biotechnology, Delft University of Technology, Julianalaan 67 a, 2628 BC Delft, The Netherlands
}

\author{
Dimitry Yu. Sorokin, ${ }^{1,2}$ Tatyana P. Tourova, ${ }^{1}$ Anatoly M. Lysenko, \\ Lubov L. Mityushina ${ }^{1}$ and J. Gijs Kuenen ${ }^{2}$ \\ Author for correspondence: Dimitry Yu. Sorokin. Tel: +7 095 1350109. Fax: +7 0951356530 \\ e-mail: soroc@inmi.da.ru
}

\begin{abstract}
Nine strains of haloalkaliphilic, obligately autotrophic, sulfur-oxidizing bacteria able to grow with thiocyanate $\left(\mathrm{SCN}^{-}\right)$as the sole energy and nitrogen source were isolated from soda lakes in South-East Siberia, Kenya and Egypt after enrichment on sodium carbonate minerals buffered at pH 10 with thiocyanate as the substrate. The isolates fell into two groups that were substantially different in terms of cell morphology, growth parameters and the ability to oxidize carbon disulfide. The bacteria were able to oxidize sulfide, polysulfide, sulfur and tetrathionate, as well as thiocyanate. Two isolates belonged to an extremely halotolerant type growing in the presence of up to $4 \mathrm{M} \mathrm{Na}^{+}$. Cyanate $\left(\mathrm{CNO}^{-}\right)$was the main nitrogen-containing intermediate during thiocyanate degradation in both groups. According to DNA-DNA hybridization data and phylogenetic analysis, both groups of isolates belong to a recently described genus of haloalkaliphilic sulfuroxidizing bacteria, i.e. Thioalkalivibrio, belonging to the $\gamma$-Proteobacteria, in which where they represent two new species. The species name Thioalkalivibrio paradoxus (type strain ARh $1^{\top}=$ DSM $13531^{\top}=J C M 11367^{\top}$ ) is proposed for the group with barrel-shaped cells, and the species name Thioalkalivibrio thiocyanoxidans (type strain ARh $2^{\top}$, DSM $13532^{\top}=$ JCM $11368^{\top}$ ) is proposed for the group with vibrio-shaped cells. The diagnosis of the genus Thioalkalivibrio is amended according to the new data.
\end{abstract}

\section{INTRODUCTION}

The ability to use thiocyanate $\left(\mathrm{SCN}^{-}\right)$as a single energy substrate is limited to few strains of neutrophilic, obligately autotrophic, sulfur-oxidizing bacteria such as Thiobacillus thioparus (Happold et al., 1954, 1958; Youatt, 1954; Katayama \& Kuraishi, 1978; Smith \& Kelly, 1988) and Thiobacillus denitrificans (De Kruyff et al., 1957), and the facultatively

Published online ahead of print on 14 December 2001 as DOI 10.1099/ ijs.0.01993-0.

The GenBank/EMBL/DDBJ accession numbers for the $16 \mathrm{~S}$ rDNA sequences of strains ARh $1^{\top}$ (= DSM $\left.13531^{\top}\right)$ and ARh $2^{\top}$ (= DSM 13532 $)$ are AF151432 and AF302081, respectively. autotrophic Paracoccus thiocyanatus (Katayama et al., 1995). Recently, a large number of alkaliphilic, obligately autotrophic, sulfur-oxidizing isolates belonging to two new genera, namely Thioalkalimicrobium and Thioalkalivibrio, in the $\gamma$-Proteobacteria have been obtained from soda lakes (Sorokin et al., 2000, 2001a). However, neither of them was capable of thiocyanate oxidation. The thiocyanate-oxidizing sulfur alkaliphiles were retrieved only by using specific enrichment with thiocyanate as the substrate. Four strains were isolated from Siberian and Kenyan soda lakes, and their properties and thiocyanate metabolism have been described recently (Sorokin et al., 2001b). Furthermore, five new thiocyanate-oxidizing strains have been obtained from the Wadi Natrun soda lakes in Egypt. 
In this paper, two new species of the genus Thioalkalivibrio are described on the basis of morphological, physiological and genetic investigations of nine strains of obligately autotrophic, sulfur-oxidizing, alkaliphilic bacteria from soda lakes.

\section{METHODS}

Samples. Three mixed sediment samples from soda lakes in South-East Siberia (1998), North-East Mongolia (1999) and Kenya (1999), and eight sediment samples from the Wadi Natrun soda lakes (2000), were used for the enrichment of thiocyanate-oxidizing alkaliphiles. The $\mathrm{pH}$ and the salt content in the lakes varied from $9 \cdot 2$ to 11.0 and from 5 to $380 \mathrm{~g}^{-1}$, respectively.

Isolation of pure cultures and cultivation. Pure cultures of thiocyanate-oxidizing alkaliphiles were obtained after enrichment on alkaline mineral medium buffered at $\mathrm{pH} 10-10 \cdot 1$ with sodium bicarbonate/carbonate buffer $\left(0.6 \mathrm{M}\right.$ total $\left.\mathrm{Na}^{+}\right)$ and supplemented with $10-15 \mathrm{mM}$ potassium thiocyanate as the sole energy, nitrogen and sulfur source (Sorokin et al., 2001a, b). After complete thiocyanate consumption (3-6 weeks), serial dilutions were performed to isolate the dominant organisms. The cultures from the maximal positive dilutions were plated on a solid medium of the same composition with $10 \mathrm{mM}$ thiocyanate or $20 \mathrm{mM}$ thiosulfate plus $5 \mathrm{mM}$ thiocyanate, and the single colonies were isolated into a soda mineral solution with $10 \mathrm{mM}$ thiocyanate to examine their ability to grow solely with thiocyanate. To investigate the influence of $\mathrm{pH}$ on the growth and oxidizing activity of washed cells, $0.1 \mathrm{M} \mathrm{HEPES} / 0.6 \mathrm{M} \mathrm{NaCl}$ (for $\mathrm{pH}$ 7-8) and sodium bicarbonate/carbonate buffer (0.6 M total $\mathrm{Na}^{+}$) (for $\mathrm{pH} \mathrm{8-10 \cdot 5)}$ were used (Sorokin et al., 2001a). The ability of the isolated pure cultures to grow anaerobically with thiosulfate and thiocyanate in the presence of nitrate as the electron acceptor $(20 \mathrm{mM})$ was studied using $50 \mathrm{ml}$ flasks with butyl rubber stoppers. Anaerobiosis was achieved by repeated evacuation/flushing with argon (five cycles). The ability to utilize $\mathrm{H}_{2}$ as the energy source was tested in closed 3.51 jars filled with a gas mixture containing $95 \% \mathrm{H}_{2}$ and $5 \% \mathrm{O}_{2}$. The methylotrophic potential was tested by growing the isolates on mineral base at $\mathrm{pH} 10$ with $10 \mathrm{mM}$ methanol, methylamine or formate as the electron donor and $5 \mathrm{mM}$ $\mathrm{NH}_{3}$ as the nitrogen source. A 1.51 laboratory fermenter equipped with $\mathrm{pH}$ and $\mathrm{pO}_{2}$ probes (Applicon) was used to grow the alkaliphiles in thiocyanate- or thiosulfate-limited continuous culture. The $\mathrm{pH}$ was maintained at $10 \cdot 0-10 \cdot 2$ and dissolved oxygen was kept at $50 \%$ air saturation. The final medium composition was the same as for batch cultivation (final thiocyanate and thiosulfate concentrations of 6-13 and $40 \mathrm{mM}$, respectively).

Analyses and electron microscopy. All chemical analyses (thiocyanate, cyanate, ammonium, thiosulfate, sulfur and protein) and the detection of cyanase activity were performed exactly as described previously (Sorokin et al., 2001b).

The total samples for electron microscopy were prepared from the cells fixed with formaldehyde (final concentration $2.5 \%, \mathrm{w} / \mathrm{v}$ ) in liquid medium and then positively stained with $1 \%(\mathrm{w} / \mathrm{v})$ phospho-tungstic acid. Cells for ultra-thin sectioning were centrifuged, washed and resuspended in $0.05 \mathrm{M}$ HEPES/0.6 M NaCl (pH 8), fixed with $1 \%(\mathrm{w} / \mathrm{v})$ final $\mathrm{OsO}_{4}$ containing $0.6 \mathrm{M} \mathrm{NaCl}$ for $12 \mathrm{~h}$ at $4{ }^{\circ} \mathrm{C}$, dehydrated and embedded into the resin. Thin sections were stained with uranyl acetate and lead citrate. To detect intracellular accumulation of elemental sulfur, cells were sedimented, stained with $2 \% \mathrm{AgNO}_{3}(\mathrm{w} / \mathrm{v})+2 \%$ glutaralaldehyde (v/v) for $10 \mathrm{~h}$ and then fixed with $\mathrm{OsO}_{4}$. Post-sectional staining was omitted in this case.

The isolation of the DNA, the determination of the $\mathrm{G}+\mathrm{C}$ content of DNA preparations, and DNA-DNA hybridization were performed according to Marmur (1961) and De Ley et al. (1970).

Amplification and sequencing of 16S rRNA genes. For amplification and sequencing of $16 \mathrm{~S}$ rRNA genes, the DNA was obtained by standard phenol/chloroform extraction. The 16S rRNA genes were selectively amplified using primers 5'-AGAGTTTGATCCTGGCTCAG-3' (forward) and 5'TACGGTTACCTTGTTACGACTT-3' (reverse). PCR products were purified from low-melting agarose by using the Wizard PCR-Prep kit (Promega) according to the manufacturer's instructions. Almost complete sequencing (14001450 nucleotides) was performed using the Promega Silver Sequencing kit (Promega) according to the manufacturer's instructions (with minor modifications).

$16 S$ rDNA sequence analysis. The sequences were aligned manually with sequences obtained from the database of small-subunit rRNAs collected from the international nucleotide sequence library EMBL. The sequences were compared with those of members of the Proteobacteria. Regions that were not sequenced in one or more reference organisms were omitted from the analyses. Pairwise evolutionary distances (expressed as estimated changes per 100 nucleotides) were computed by using the Jukes \& Cantor method. The resulting phylogenetic tree was constructed by using the neighbour-joining method. Bootstrap analysis (100 replications) was used to validate the reproducibility of the branching patterns of the trees.

\section{RESULTS}

\section{Isolation of pure cultures}

Stable enrichment cultures with thiocyanate at $\mathrm{pH} 10$ were obtained from the mixed Siberian and Kenyan samples and from four out of eight Wadi Natrun samples. Thiocyanate consumption was also observed in the enrichment inoculated with the composite sediment sample from Mongolian soda lakes, but it was not stable in further passages.

Both the Kenyan and the Siberian enrichments included large non-motile rods containing sulfur globules inside the cells (phenotype 1) and short, actively moving vibrios (phenotype 2) which dominated numerically in subsequent serial dilutions on mineral medium with thiocyanate. In the Wadi Natrun samples, phenotype 1 was highly dominant. The colonial growth on thiocyanate alkaline agar was very slow. The colonies became visible only after $10 \mathrm{~d}$, while in the presence of thiosulfate the growth had already appeared after $5 \mathrm{~d}$. The bacteria of phenotype 1 formed $1-1.5 \mathrm{~mm}$, white, slimy, sulfur-containing colonies on thiocyanate and dome-like colonies (up to $3 \mathrm{~mm}$ ) in the presence of thiosulfate. Aged colonies became almost transparent and reddish. The bacteria of phenotype 2 formed flat, transparent colonies (up to $1 \mathrm{~mm}$ ) on $\mathrm{CNS}^{-}$agar, and white, refractile, sulfurcontaining colonies $(2-3 \mathrm{~mm}$, and which gradually turned transparent and, in some cases, yellowish) on thiosulfate $+\mathrm{CNS}^{-}$agar. Overall, nine strains of bac- 
Table 1. Properties of pure cultures of alkaliphilic, thiocyanate-oxidizing autotrophs from soda lakes

\begin{tabular}{|c|c|c|c|c|c|}
\hline Source & Phenotype* & Strain & $\begin{array}{c}\mathrm{NO}_{3}^{-}, \mathrm{NO}_{3}^{-} \\
\text {assimilation } \\
\text { (growth with } \\
\quad \mathrm{S}_{2} \mathrm{O}_{3}^{2-} \text { ) }\end{array}$ & $\begin{array}{l}\text { Cyanase } \\
\text { activity }\end{array}$ & $\begin{array}{c}\text { Growth at } \\
2-4 \mathrm{M} \mathrm{Na} \mathrm{a}^{+} \\
\text {and yellow } \\
\text { pigment }\end{array}$ \\
\hline SE Siberia (5 subsamples) & 2 & ARh 4 & + & + & - \\
\hline \multirow[t]{3}{*}{ Kenya (8 subsamples) } & 1 & $\mathrm{ARh} 1^{\mathrm{T}}$ & - & - & - \\
\hline & 2 & $\mathrm{ARh} 2^{\mathrm{T}}$ & + & - & + \\
\hline & & ARh 3 & - & - & + \\
\hline \multicolumn{6}{|l|}{ Wadi an Natrun } \\
\hline \multirow[t]{2}{*}{ Lake Fazda } & 2 & ARh 5 & + & + & - \\
\hline & 1 & ARh 6 & weak & - & - \\
\hline Lake Zugm & 1 & ARh 7 & - & - & - \\
\hline Lake Ruzita & 1 & ARh 8 & - & - & - \\
\hline Lake Gaara & 1 & ARh 9 & - & - & - \\
\hline
\end{tabular}

* Phenotype 1 is represented by the isolates with rod-shaped non-motile cells; phenotype 2 includes isolates with vibroid motile cells.
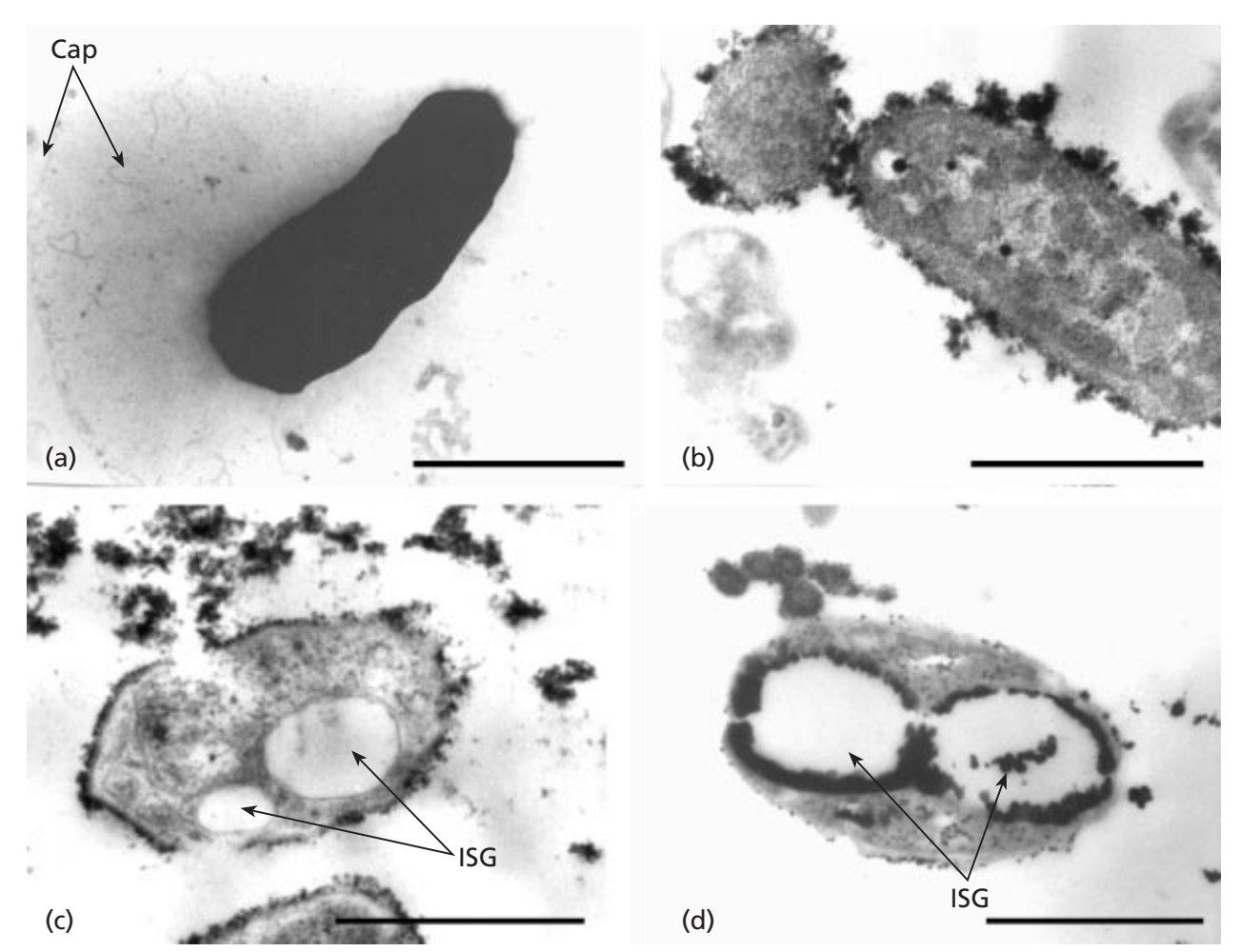

Fig. 1. Cell morphology of phenotype 1 (strain $A R h 1^{T}$ ) thiocyanate-oxidizing alkaliphilic bacteria grown with thiocyanate $(a, b)$ or thiosulfate $(c, d)$ as energy substrates at $\mathrm{pH}$ 10. (a) Total preparation; (b, c) thin sections stained with uranyl acetate + lead citrate; (d) thin section specifically stained with $\mathrm{Ag}^{+}$for detection of intracellular sulfur. Cap, capsule; ISG, intracellular sulfur globules. Bars, $1 \mu \mathrm{m}$.

teria able to grow with thiocyanate as the sole energy, nitrogen and sulfur source at $\mathrm{pH} 10$ and at a salt concentration of $0.6 \mathrm{M} \mathrm{Na}^{+}$have been isolated in pure culture from soda-lake sediments. Five strains belonged to phenotype 1 and four strains belonged to phenotype 2 (Table 1).

\section{Cell morphology}

The rod-shaped isolates of phenotype 1 had large, nonmotile, barrel-like cells $(0 \cdot 6-1 \times 1-2 \mu \mathrm{m})$ covered by thick capsular material (Fig. 1a, b). During growth with thiocyanate and thiosulfate, elemental sulfur was 


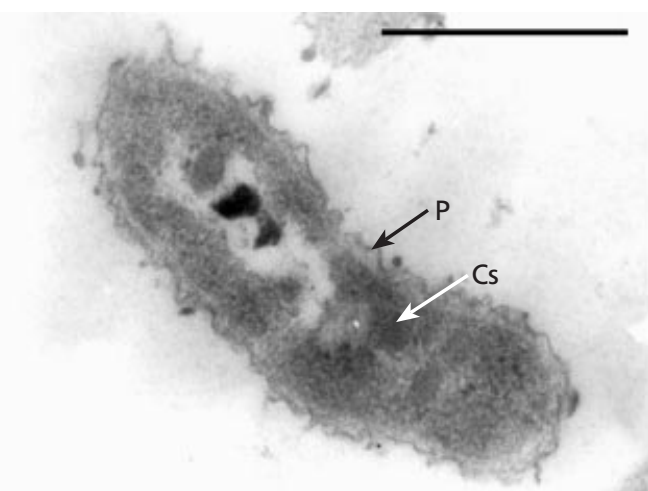

(a)

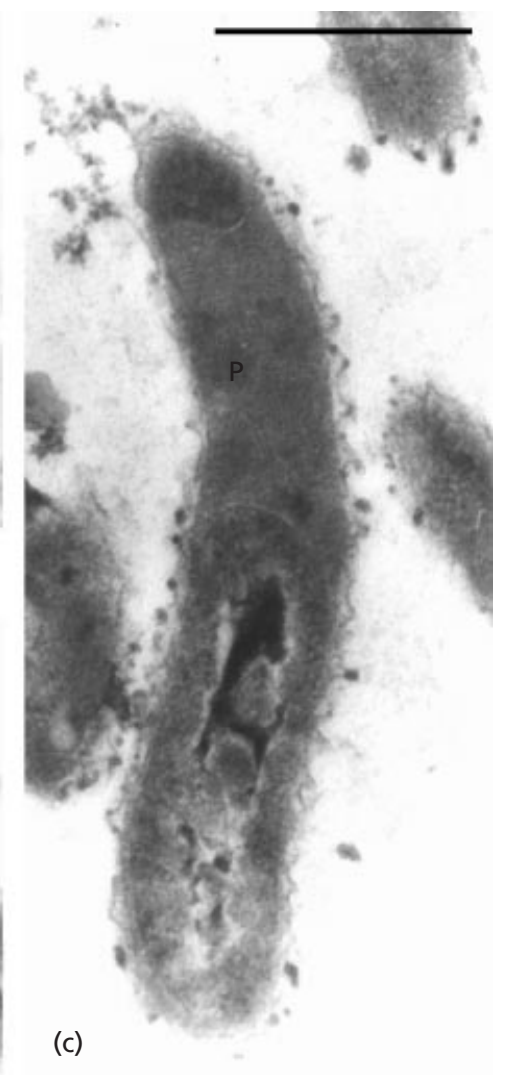

(b)

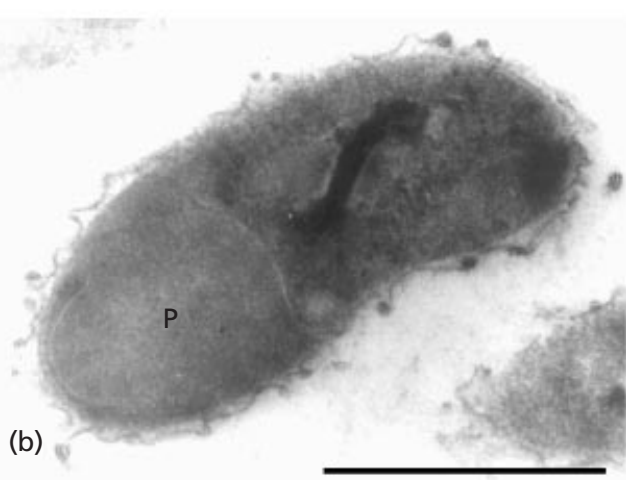

(c)

Fig. 2. Cell morphology of phenotype 2 (strain $A R h 2^{\top}$ ) thiocyanate-oxidizing alkaliphilic bacteria (ultrathin sections) grown at $\mathrm{pH} 10$ with thiosulfate $(\mathrm{a})$ or thiocyanate $(\mathrm{b}, \mathrm{c})$ as the energy substrate. $\mathrm{P}$, periplasmic compartment; Cs, carboxysome-like structures. Bar, $0.5 \mu \mathrm{m}$.

produced heavily inside the cells, the intracellular sulfur globules each being surrounded by a membrane; this is similar to the situation in purple sulfur bacteria (Fig. 1c, d). When the cells with sulfur inclusions were separated from the medium and incubated in anaerobic soda buffer, the sulfur was reduced to sulfide, which immediately reacted with the cellular iron to form black iron sulfide. The cells of the phenotype 2 strains were motile vibrios $(0.5-0.6 \times 0.8-1.4 \mu \mathrm{m})$ each having one polar flagellum. The ultrastructure of cells grown with thiosulfate was typical of the autotrophic sulfur bacteria, e.g. with an undulating cell wall and multiple carboxysomes (Fig. 2a). In contrast, the thiocyanate-grown cells of phenotype 2 strains lacked carboxysomes and had unusually large periplasmic compartments (Fig. 2b, c).

\section{Metabolic properties}

All of the strains isolated were obligately chemolithoautotrophic. They were able to grow with thiocyanate and inorganic sulfur compounds, such as thiosulfate or sulfide, as electron donors on carbonate minerals. Although additions of yeast extract or peptone stimulated growth, no growth occurred without inorganic sulfur compounds. The bacteria were unable to grow with hydrogen, methanol, methylamine or formate as electron donors, or anaerobically with nitrate, nitrite or $\mathrm{N}_{2} \mathrm{O}$ as electron acceptors. Only four strains can assimilate nitrate or nitrite as nitrogen source, but all of them can use ammonia when it is supplied at $<5 \mathrm{mM}$. Only two phenotype 2 strains possessed a cyanase activity (which converts cyanate to ammonia and $\mathrm{CO}_{2}$ ) which was expressed during growth with thiosulfate as electron donor but not in thiocyanategrown cells (Table 1). The presence of cyanase correlated with the ability of strains ARh 4 and ARh 5 to grow well on the mixture of thiosulfate and thiocyanate. Strains ARh $2^{\mathrm{T}}$ and ARh 3 (both phenotype 2) differed from the other isolates by having the potential to grow in extremely high concentrations of sodium carbonate. With thiocyanate as the energy substrate, they grew in total $\mathrm{Na}^{+}$concentrations up to $2.5 \mathrm{M}$; with thiosulfate, they grew in concentrations up to a level reaching sodium carbonate saturation $(4.3 \mathrm{M}$ $\mathrm{Na}^{+}$). Both strains produced a membrane-bound yellow pigment with an absorbtion maximum in methanol of approximately $430 \mathrm{~nm}$, thus resembling previously described extremely natronotolerant strains of the genus Thioalkalivibrio (Sorokin et al. 2001a). The other strains grew well within a salt range of $0 \cdot 3-1 \mathrm{M}$ total $\mathrm{Na}^{+}$. 
Table 2. Substrate-dependent oxygen consumption by washed cells of thiocyanateoxidizing alkaliphilic autotrophs grown with thiocyanate or thiosulfate at $\mathrm{pH} 10.0$

Values are maximum respiration rate (minus endogenous) at $\mathrm{pH} 10 \cdot 0, \mathrm{nmol} \mathrm{O}_{2}(\mathrm{mg}$ protein $)^{-1} \min ^{-1}$; mean results from two or three independent measurements.

\begin{tabular}{|c|c|c|c|c|}
\hline \multirow[t]{2}{*}{ Substrate } & \multicolumn{2}{|c|}{ Phenotype $1\left(\mathrm{ARh} 1^{\mathrm{T}}\right)$ grown on: } & \multicolumn{2}{|c|}{ Phenotype $2\left(\mathrm{ARh} 2^{\mathrm{T}}\right)$ grown on: } \\
\hline & $\mathbf{S C N}^{-}$ & $\mathrm{S}_{2} \mathrm{O}_{3}^{2-}$ & $\mathbf{S C N}^{-}$ & $\mathrm{S}_{2} \mathrm{O}_{3}^{2-}$ \\
\hline $\mathrm{NCS}^{-}$ & 160 & 0 & 300 & 0 \\
\hline $\mathrm{CS}_{2}$ & 90 & $0-12$ & 0 & 0 \\
\hline $\mathrm{S}_{2} \mathrm{O}_{3}^{2-}$ & 580 & 350 & 580 & 360 \\
\hline $\mathrm{HS}^{-}$ & 2900 & 3800 & 1400 & 850 \\
\hline $\mathrm{S}_{6}^{2-}$ (polysulfide) & 400 & 2600 & 960 & 450 \\
\hline $\mathrm{S}_{8}$ (sulfur) & 50 & 50 & 450 & 330 \\
\hline $\mathrm{S}_{4} \mathrm{O}_{6}^{2-}$ (at pH 9) & 0 & 0 & 90 & 200 \\
\hline
\end{tabular}

\section{Growth and activity parameters}

In batch culture at $\mathrm{pH} 10$, the phenotype 1 strains accumulated large amounts of elemental sulfur inside the cells, both with thiocyanate and with thiosulfate, during the initial growth phase. When more than $80 \%$ of the substrate was consumed, sulfur started to disappear, and, finally, sulfate accumulated as the product. In thiocyanate-limited continuous culture, sulfur accumulated only at suboptimal dilution rates close to $\mu_{\max }$ (maximum specific growth rate). Among the phenotype 2 strains, only strains ARh $2^{\mathrm{T}}$ and ARh 4 occasionally formed small amounts of extracellular sulfur during growth on thiosulfate (but never on thiocyanate). Phenotype 1 strains differed from phenotype 2 strains by having higher growth rates and specific growth yields on thiocyanate. Maximal values of $\mu$ and $Y$ (growth yield coefficient) obtained in thiocyanate-limited continuous cultures at $\mathrm{pH} 10-10 \cdot 2$ were $0.08-0 \cdot 1 \mathrm{~h}^{-1}$ and $8-10.5 \mathrm{mg}$ protein $\mathrm{mmol}^{-1}$, respectively, for strain ARh $1^{\mathrm{T}}$, and $0.03-0.042 \mathrm{~h}^{-1}$ and $5.5-6.8 \mathrm{mg}$ protein $\mathrm{mmol}^{-1}$ for strains ARh $2^{\mathrm{T}}$ and ARh 4. Perhaps the faster growth of phenotype 1 might explain the ubiquitous dominance of these bacteria in thiocyanate enrichments from the various soda lakes. Both types grew well at thiocyanate concentrations up to $15 \mathrm{mM}$. At $30 \mathrm{mM}$ thiocyanate, growth at pH 10 was completely arrested. On the other hand, the vibrio strains grew faster with thiosulfate as the energy source than did phenotype 1 isolates $(0 \cdot 08-1$ versus $0 \cdot 01-0 \cdot 015 \mathrm{~h}^{-1}$, respectively).

Cyanase activity was either absent or blocked in alkaliphilic isolates during growth on thiocyanate. This resulted in accumulation of cyanate $(\mathrm{O}=\mathrm{C}=$ $\mathrm{N}^{-}$) in the culture supernatants as the main nitrogencontaining intermediate of thiocyanate decomposition. Taking into account the sufficient chemical stability of cyanate in alkaline medium, this mechanism apparently allowed the alkaliphiles to avoid immediate accumulation of free ammonia up to a toxic level (2-3 mM at $\mathrm{pH} 10)$.

Respiratory tests with washed cell suspensions demon- strated that the thiocyanate-oxidizing pathway was inducible in both phenotypes (Table 2), e.g. cells grown with thiosulfate were unable to oxidize thiocyanate. Phenotype 1 strains, in addition to oxidizing thiocyanate and thiosulfate, oxidized sulfide and polysulfide at high rates. On the other hand, the oxidation of elemental sulfur was extremely slow, while tetrathionate was not metabolized at all. Furthermore, this type had the unique capacity to oxidize carbon disulfide $\left(\mathrm{CS}_{2}\right)$, which was induced during growth with thiocyanate. Elemental sulfur was the main product of sulfur-compound oxidation by washed cells of phenotype 1 strains, in contrast to phenotype 2 strains, which performed complete oxidation to sulfate. The latter lacked the capacity for carbon disulfide oxidation but had relatively high rates of elemental sulfur and tetrathionate oxidation (Table 2). Sulfite-oxidizing activity was not detectable in either phenotype.

\section{Influence of pH on growth and oxidizing activity}

The soda-lake isolates grew well with thiocyanate within the narrow $\mathrm{pH}$ range $9 \cdot 5-10 \cdot 2$, the optimum being at $\mathrm{pH} 9 \cdot 8-10 \cdot 0$. With thiosulfate, the range was broader (from $\mathrm{pH} 8.5$ to $10 \cdot 5$ ). In thiocyanate-limited chemostat cultures, the highest growth rates for strains $\mathrm{ARh} 1^{\mathrm{T}}$ and $\mathrm{ARh} 4$ were obtained at $\mathrm{pH} 10 \cdot 2$. The $\mathrm{pH}$ profiles for the respiratory activity with various sulfur compounds in general corresponded with those for growth, except that they were wider at the extremes, e.g. activity was still detectable at $\mathrm{pH}$ values lower than 8.0 and higher than $10 \cdot 8$. These results demonstrated that the soda-lake thiocyanate-oxidizing isolates are obligate alkaliphilic bacteria.

\section{Genetic and phylogenetic analysis}

DNA-DNA hybridization demonstrated a high level of homology between phenotype 1 strains. The Wadi Natrun isolates ARh 6 to ARh 9 showed $>90 \%$ similarity to each other, and their homology with the Kenyan isolate ARh $1^{\mathrm{T}}$ was $70-73 \%$. This indicates 
Table 3. DNA-DNA homology between thiocyanate-oxidizing isolates from the soda lakes, and their similarity to sulfur-oxidizing alkaliphiles of the genus Thioalkalivibrio

\begin{tabular}{|c|c|c|c|c|c|c|c|}
\hline \multirow[t]{2}{*}{ Strain } & \multirow{2}{*}{$\begin{array}{c}\text { DNA G }+\mathbf{C} \\
\text { content }\left(T_{\mathrm{m}}, \mathbf{m o l} \%\right)\end{array}$} & \multicolumn{6}{|c|}{ DNA-DNA homology (\%) with: } \\
\hline & & ARh $1^{T}$ & $\operatorname{ARh} 2^{\mathrm{T}}$ & AL 2* & ALJ 6 & ALJ $12 \dagger$ & ALJ 15 \\
\hline ARh $1^{\mathrm{T}}$ & $65 \cdot 6$ & & & 30 & 20 & 21 & 26 \\
\hline ARh 6 & $66 \cdot 2$ & 71 & & & & & \\
\hline $\mathrm{ARh} 2^{\mathrm{T}}$ & $66 \cdot 2$ & 30 & & 45 & 42 & 51 & 65 \\
\hline ARh 3 & $66 \cdot 9$ & 30 & 90 & & & & \\
\hline ARh 4 & $66 \cdot 4$ & 28 & 61 & 60 & 44 & 58 & 48 \\
\hline ARh 5 & $66 \cdot 2$ & 25 & 66 & & & & \\
\hline
\end{tabular}

* Type strain of Thioalkalivibrio versutus.

$\dagger$ Type strain of Thioalkalivibrio nitratis.

\$ Extremely natronotolerant, yellow-coloured representative of Thioalkalivibrio versutus.

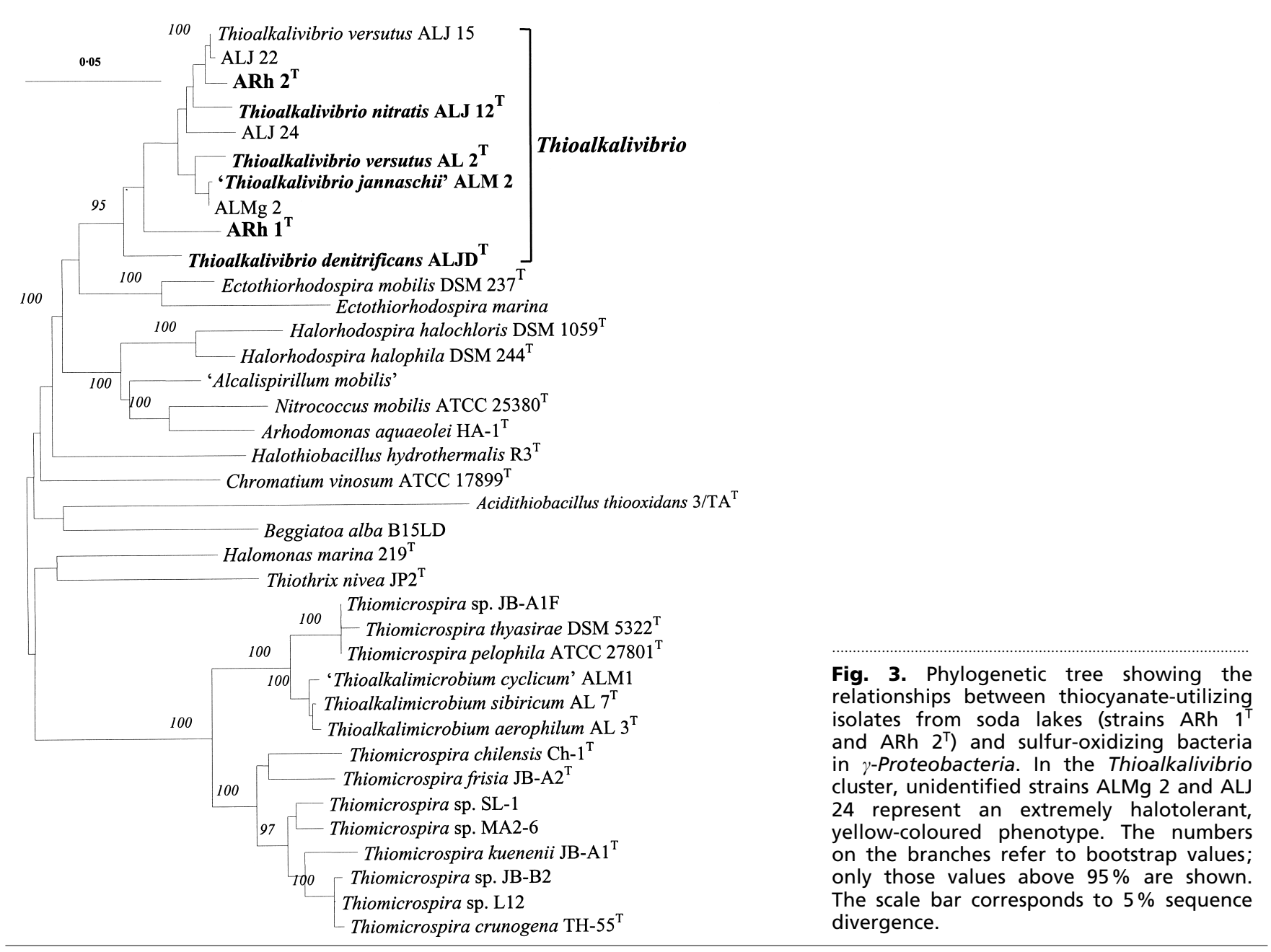

that all phenotype 1 strains belong to the same genespecies, which is in agreement with their general phenotypic similarity. Among the phenotype 2 isolates, two genetically close subgroups can be distinguished: strains ARh $2^{\mathrm{T}}$ and ARh $3(90 \%$ DNA homology), and strains ARh 4 and ARh 5 (70\% DNA homology). Therefore, in further comparisons only strains ARh $2^{\mathrm{T}}$ and ARh 4 were used. The similarity between the phenotype 2 strains ARh $2^{\mathrm{T}}$ and ARh 4 was $61 \%$. The homology between phenotype 1 and 2 was $28-31 \%$, which clearly indicates their different species status (Table 3 ). 
The phylogenetic analysis of representative strains from two phenotypes (ARh $1^{\mathrm{T}}$ and ARh $2^{\mathrm{T}}$ ) demonstrated that both are members of the recently described genus Thioalkalivibrio within the $\gamma$-Proteobacteria accommodating the alkaliphilic, obligately autotrophic, sulfur-oxidizing bacteria from soda lakes (Fig. 3). The level of sequence similarity $(94 \cdot 0-97 \cdot 5 \%)$ was within the range of the genus Thioalkalivibrio.

DNA-DNA hybridization between representative thiocyanate-oxidizing strains and members of Thioalkalivibrio indicated a clear relatedness for phenotype 2 with respect to this genus ( $45-65 \%$ homology), and relatively low level of homology $(<30 \%)$ for phenotype 1 which was in the same order as that between phenotypes 1 and 2 (Table 3 ).

\section{DISCUSSION}

Our investigation revealed the presence, in soda lakes, of two types of haloalkaliphilic autotrophic bacteria able to grow with thiocyanate as the sole energy, nitrogen and sulfur source; these bacteria belong to the $\gamma$-Proteobacteria. They differed, therefore, from the known neutrophilic, sulfur-oxidizing autotrophs not only by their high degree of $\mathrm{pH}$ - and salt-tolerance but also phylogenetically (the neutrophiles belong to the $\beta$-Proteobacteria).

One group of thiocyanate-utilizing alkaliphiles with vibrio-shaped cells clearly resembled, in many respects, the members of the recently described alkaliphilic, sulfur-oxidizing genus Thioalkalivibrio (Sorokin et al., 2001a). This is in agreement with the relatively high level of DNA homology typical of species of the same genus. In particular, strains $\mathrm{ARh} 2^{\mathrm{T}}$ and $\mathrm{ARh} 3$ are typical representatives of the extremely natronotolerant subgroup of the genus Thioalkalivibrio characterized by the ability to grow in soda brines and by the presence of a membrane-bound yellow pigment. However, the ability to utilize thiocyanate as the energy substrate seems to be a very specific phenotypic trait because none of the strains isolated with thiosulfate were able to utilize thiocyanate as an energy source. Therefore, it seems reasonable to position the thiocyanate-utilizing vibrio strains into a separate species, despite their relatively high genetic similarity to the other strains of Thioalkalivibrio unable to use thiocyanate.

Another group of thiocyanate-utilizing alkaliphiles with rod-shaped cells differed substantially from the representatives of Thioalkalivibrio. The former bacteria had a quite different cell morphology, a very low capacity for elemental sulfur oxidation, and the ability to oxidize thiocyanate and carbon disulfide. The very low level of its DNA homology with members of Thioalkalivibrio $(30 \%)$ indicates a low level of relatedness. Nevertheless, the phylogenetic data clearly demonstrated that the phenotype 1 thiocyanate-oxidizing isolates belong to the genus Thioalkalivibrio as well.

On the basis of these data, we propose two new species in the genus Thioalkalivibrio, to accommodate the thiocyanate-oxidizing alkaliphiles. The names Thioalkalivibrio paradoxus and Thioalkalivibrio thiocyanoxidans are proposed for the phenotype 1 and 2 strains, respectively.

\section{Description of Thioalkalivibrio thiocyanoxidans sp. nov.}

Thioalkalivibrio thiocyanoxidans (thi.o.cy.an.ox'i. dans. Gr. n. thios sulfur; Gr. adj. cyan blue; N.L. n. thiocyanatum thiocyanate; N.L. v. oxido to oxidize; N.L. part. adj. thiocyanoxidans oxidizing thiocyanate).

The cells are short vibrios $(0.5-0.6 \times 0.8-1.4 \mu \mathrm{m})$, and each has a single polar flagellum. Thiocyanate-grown cells have extended periplasmic compartments. Obligately alkaliphilic. Growth is possible within the salinity range $0 \cdot 3-1 \mathrm{M} \mathrm{Na}^{+}$total salts, and for some strains growth is possible at concentrations up to $4 \cdot 3 \mathrm{M}$. The extremely salt-tolerant strains produce a membrane-bound yellow pigment. Obligately chemolithoautotrophic. Differs from the other Thioalkalivibrio species by the ability to grow with thiocyanate as the sole energy, nitrogen and sulfur source, producing cyanate as an intermediate. Also oxidizes sulfide, thiosulfate, polysulfide, elemental sulfur and tetrathionate to sulfate. Does not oxidize carbon disulfide. Some strains have cyanase activity. The $\mathrm{G}+\mathrm{C}$ content of the DNA (four strains) is $66 \cdot 2-66.9 \mathrm{~mol} \%\left(T_{\mathrm{m}}\right)$. Isolated from soda-lake sediments. Other properties are as for the genus. The type strain, ARh $2^{\mathrm{T}}(=\mathrm{DSM}$ $\left.13532^{\mathrm{T}}=\mathrm{JCM} 11368^{\mathrm{T}}\right)$, is a yellow-coloured, extremely natronotolerant bacterium able to grow in soda brines (up to $4 \cdot 3 \mathrm{M} \mathrm{Na}^{+}$). Cyanase activity is absent. DNA $\mathrm{G}+\mathrm{C}$ content is $66.2 \mathrm{~mol} \%\left(T_{\mathrm{m}}\right)$. Isolated from a Kenyan soda lake. The GenBank $16 \mathrm{~S}$ rDNA sequence accession number is AF302081.

\section{Description of Thioalkalivibrio paradoxus sp. nov.}

Thioalkalivibrio paradoxus (par.a.do'xus. Gr. adj. paradoxos unbelievable, strange).

The cells are large, non-motile, barrel-like rods $(0 \cdot 8$ $1 \times 1 \cdot 2-2 \mu \mathrm{m})$ with capsules. Able to grow with thiocyanate as the sole energy, nitrogen and sulfur source. During growth with thiocyanate and thiosulfate, they form sulfur globules, each surrounded by a membrane, inside the cells. The sulfur is oxidized slowly further to sulfate. Produces cyanate as the nitrogen-containing intermediate during thiocyanate degradation. Obligately alkaliphilic and moderately halophilic. Does not possess cyanase and assimilatory nitrate-reductase activities. Apart from thiocyanate, oxidizes sulfide, thiosulfate, polysulfide and carbon disulfide. The elemental sulfur oxidation activity is extremely low. The $\mathrm{G}+\mathrm{C}$ content of the DNA (five strains) is 65.6-66.4 mol\% $\left(T_{\mathrm{m}}\right)$. Isolated from the sediments of Kenyan (strain ARh $1^{\mathrm{T}}$ ) and Egyptian ( strains ARh 6 to ARh9) soda lakes. Other properties are as for the genus. The type strain is ARh $1^{\mathrm{T}}=\mathrm{DSM} 13531^{\mathrm{T}}=$ 
JCM $11367^{\mathrm{T}}$ ); DNA $\mathrm{G}+\mathrm{C}$ content is $65.6 \mathrm{~mol} \%$ $\left(T_{\mathrm{m}}\right)$. The GenBank 16S rDNA sequence accession number is AF151432.

\section{Modification of the diagnosis of the genus Thioalkalivibrio}

The genus mostly includes strains with vibroid cells each of which is motile by means of a single polar flagellum. It also may include strains with non-motile, barrel-like cells with thick capsules. Some strains can utilize thiocyanate as the sole energy source, and some thiocyanate-utilizing strains can oxidize carbon disulfide.

\section{ACKNOWLEDGEMENTS}

This work (project 047.006.018) was financially supported by The Netherlands Organization for Scientific Research (NWO) and by RFBR (99-04-48360, 01-04-48782).

\section{REFERENCES}

De Kruyff, C. D., van der Walt, J. I. \& Schwartz, H. M. (1957). The utilization of thiocyanate and nitrate by thiobacilli. Antonie Leeuwenhoek 23, 305-316.

De Ley, J., Caffon, H. \& Reinaerts, A. (1970). The quantitative measurements of hybridization DNA from renaturation rates. Eur $J$ Biochem 12, 133-140.
Happold, F. C., Johnstone, K. I., Roger, H. S. \& Youatt, J. B. (1954). The isolation and characteristics of an organism oxidizing thiocyanate. J Gen Microbiol 10, 261-266.

Happold, F. C., Jones, G. L. \& Pratt, D. B. (1958). Utilization of thiocyanate by Thiobacillus thioparus and T. thiocyanooxidans. Nature 182, 266-267.

Katayama, Y. \& Kuraishi, H. (1978). Characteristics of Thiobacillus thioparus and its thiocyanate assimilation. Can J Microbiol 24, 804-810.

Katayama, Y., Hiraishi, A. \& Kuraishi, H. (1995). Paracoccus thiocyanatus sp. nov., a new species of thiocyanate-utilizing facultative chemolithotroph, and transfer of Thiobacillus versutus to the genus Paracoccus as Paracoccus versutus comb. nov. with emendation of the genus. Microbiology 141, 1469-1477.

Marmur, J. (1961). A procedure for isolation of DNA from microorganisms. J Mol Biol 3, 208-214.

Smith, N. A. \& Kelly, D. P. (1988). Oxidation of carbon disulfide as the sole source of energy for the autotrophic growth of Thiobacillus thioparus strain TK-m. J Gen Microbiol 134, 3041-3048.

Sorokin, D. Y., Robertson, L. A. \& Kuenen, J. G. (2000). Isolation and characterization of obligately chemolithoautotrophic alkaliphilic sulfur-oxidizing bacteria. Antonie Leeuwenhoek 77, 251-260.

Sorokin, D. Yu., Lysenko, A. M., Mityushina, L. L., Tourova, T. P., Jones, B. E., Rainey, F. A., Robertson, L. A. \& Kuenen, J. G. (2001a). Thioalkalimicrobium sibiricum, Thioalkalimicrobium aerophilum gen. nov., sp. nov., and Thioalkalivibrio versutus, Thioalkalivibrio nitratis, Thioalkalivibrio denitrificans gen. nov., sp. nov., new obligately alkaliphilic and obligately chemolithoautotrophic sulfur-oxidizing bacteria from soda lakes. Int J Syst Evol Microbiol 51, 565-580.

Sorokin, D. Yu., Tourova, T. P., Lysenko, A. M. \& Kuenen, J. G. (2001b). Microbial thiocyanate utilization under highly alkaline conditions. Appl Environ Microbiol 67, 528-538.

Youatt, J. B. (1954). Studies on the metabolism of Thiobacillus thiocyanooxidans. J Gen Microbiol 11, 139-149. 